\title{
MECANISMO DE INFECÇÃO DO FUNGO Metarhizium anisopliae NO CARRAPATO Boophilus microplus EM CONDIÇÕES EXPERIMENTAIS
}

\author{
THE PENETRATION OF THE FUNGUS Metarhizium anisopliae \\ ON Boophilus microplus IN EXPERIMENTAL CONDITIONS
}

\author{
Vânia Rita Elias Pinheiro Bittencourt ${ }^{1}$ Andréa Gemal Mascarenhas ${ }^{2}$ João Luiz Horacio Faccini ${ }^{1}$
}

\section{- NOTA -}

\section{RESUMO}

O objetivo do presente trabalho foi avaliar o mecanismo de penetração do fungo Metarhizium anisopliae em Boophilus microplus em condições experimentais. As infecções foram realizadas utilizando amostra de $\boldsymbol{M}$. anisopliae isolada de carrapatos. A suspensão de conídios do fungo foi preparada utilizando água destilada e espalhante adesivo Tween 80 e foi quantificada na concentração de $10^{8}$ conídios $/ \mathrm{ml}$. As fêmeas ingurgitadas foram banhadas nesta suspensão durante cinco minutos e, após este período, foram levadas à câmara climatizada. Três dias após a infecção, as fêmeas foram fixadas utilizando tetróxido de ósmio e glutaraldeído, posteriormente desidratadas em bateria de álcool etílico com acetona. Após a desidratação, esse material foi levado à metalização e ao microscópio eletrônico de varredura, onde se observou a fixação dos conídios na cutícula das fêmeas, havendo germinação e a dilatação da extremidade do tubo germinativo em todas as amostras. Esta dilatação observada foi devido à formação do apressório, apesar de não ser possível observar esta estrutura sobre a cutícula das fêmeas ingurgitadas. $O$ tetróxido de ósmio mostrou ser um excelente fixador para fungos, enquanto o glutaraldeído mostrou ser eficiente na fixação do artrópode. Conclui-se que a forma principal de penetração deste entomopatógeno em B. microplus é através da cutícula. Cabe aqui frisar que esta é a primeira vez que é descrito o mecanismo de penetração de M. anisopliae em carrapatos.

Palavras-chave: Metarhizium anisopliae, Boophilus microplus, controle biológico.

\section{SUMMARY}

The objective of the present communication has been to draw attention to the mode of penetration of the fungus Metarhizium anisopliae through the cuticle of Boophilus microplus under experimental conditions. Samples of $\boldsymbol{M}$. anisopliae isolated from naturally infected ticks were used to prepare a suspension of $10^{8}$ conidia/ml in a destilled water with $2 \%$ of Tween 80 . The engorged females were submergged in this suspension for five minutes, then transferred to $27 \pm 1^{\circ} \mathrm{C}$ and $\geq$ $80 \%$ RH in climatized chamber. Three days after the infection, females were fixed in either osmium tetroxide or glutaraldehyde, and dehydrated in alcohol / acetone for SEM. Fixation of conidia in the cuticle, formation of germinative tube and appressoria were seem. It was suggested that the penetration of this entomopathogenic fungus is primarily through the cuticle. The fixation of the fungus for SEM was best accomplished by the osmium tetroxide whereas the glutaraldehyde was more efficient fixative for the tick. It is the first time that the penetration's mechanism of M. anisopliae is described in ticks.

Key words: Metarhizium anisopliae, Boophilus microplus, biological control.

O carrapato Boophilus microplus (Canestrini, 1887) possui elevada importância para a pecuária brasileira. Essa espécie, além de causar espoliação sangüínea através do hematofagismo, lesa o couro e é o principal transmissor de agentes patogênicos para os bovinos. No Brasil, já foram realizados experimentos visando ao controle biológico do B. microplus utilizando predadores naturais. Quanto ao controle microbiano desta espécie de carrapato, apenas dois patógenos foram estudados no Brasil: o fungo Metarhizium anisopliae foi avaliado em laboratório por BITTENCOURT et al., (1994a, b), que verificaram elevada mortalidade em ovos, larvas e fêmeas ingurgitadas, e a bactéria Cedecea lapagei foi

\footnotetext{
${ }^{1}$ Médico Veterinário, PhD, Departamento de Parasitologia Animal, Universidade Federal Rural do Rio de Janeiro, BR 465, Km 7 , 23890-000, Seropédica, RJ. E-mail: vaniabit@ufrrj.br. Autor para correspondência.

${ }^{2}$ Acadêmica de Medicina Veterinária - UFRRJ, Bolsista Iniciação Científica CNPq. 
estudada por BRUM (1989), que afirmou ser a mesma capaz de destruir o epitélio vaginal de fêmeas ingurgitadas, levando-as à morte. Deve-se lembrar que o Brasil possui clima do tipo tropical e subtropical, portanto, ideal para o desenvolvimento de patógenos na natureza de forma endêmica. Em países de clima temperado, várias espécies de fungos entomopatogênicos, que causam infecções em carrapatos das famílias Ixodidae e Argasidae já foram estudados. Entre elas pode-se citar o Aspergillus fumigatus, A. niger, Beauveria bassiana e Penicillium insectivorum. LIPA (1971) relatou que a importância de patógenos no controle de ácaros e carrapatos já foi demonstrada por vários pesquisadores, citando algumas epizootias causadas por vírus, protozoários e fungos. Em resposta à utilização indiscriminada de produtos químicos, os quais vêm provocando danos aos ecossistemas, e aliado à necessidade do homem encontrar novas alternativas para o controle de artrópodes, o controle microbiano vem se destacando, principalmente, na área de entomologia agrícola. A importância da verificação da forma de penetração dos fungos no hospedeiro invertebrado está relacionada principalmente com a formulação do fungo entomopatogênico a ser utilizada a campo, visando torná-la adequada às necessidades do fungo, para promover a infecção dos vários estádios do carrapato no meio ambiente. BITTENCOURT et $\boldsymbol{a l}$. (1995a) constataram que a principal forma de penetração do $\boldsymbol{M}$. anisopliae em $\boldsymbol{B}$. microplus é pelo tegumento, visto que em seu experimento não evidenciou a infecção dos carrapatos pelas cavidades naturais através de técnicas histológicas. O objetivo deste trabalho foi verificar a forma de penetração do fungo $\boldsymbol{M}$. anisopliae na cutícula do B. microplus, através da microscopia eletrônica de varredura, após infecção experimental.

As fêmeas ingurgitadas de $\boldsymbol{B}$. microplus foram coletadas de animais naturalmente infestados, sem tratamento com carrapaticidas há mais de vinte dias. Após a coleta, as fêmeas ingurgitadas foram acondicionadas em sacos plásticos e levadas ao laboratório, onde foram selecionadas, pesadas e acondicionadas em placas de Petri. As infecções in vitro foram realizadas utilizando amostras de $\boldsymbol{M}$. anisopliae isolada de carrapatos e identificada como isolado 959. As suspensões de conídios foram preparadas em concentrações de $10^{8}$ conídios por mililitro de suspensão, utilizando água destilada e espalhante adesivo Tween 80. As fêmeas ingurgitadas foram banhadas nessa suspensão de conídios utilizando metodologia descrita por DRUMMOND et al. (1971). Após a infecção das fêmeas ingurgitadas, as amostras foram preparadas para análise através de técnica de microscopia eletrônica de varredura. As fêmeas infectadas foram utilizadas no terceiro dia após a infecção com o entomopatógeno, sendo fixadas no vapor de uma solução de tetróxido de ósmio a $1 \%$. Foram utilizados $5 \mathrm{ml}$ desta solução colocada em becker no fundo de um dessecador, as fêmeas ingurgitadas foram colocadas em placa de Petri neste mesmo dessecador que foi tampado posteriormente. Todo o processamento foi realizado em câmara de exaustão, onde o conjunto permaneceu durante 96 horas (QUATTLEBAUM \& CARNER, 1980). A sonicação do material não foi realizada para não retirar os conídios aderidos na cutícula das fêmeas, portanto, todo o material teve de ser processado com partículas de sujeira, o que dificultou a observação da germinação de conídios. Posteriormente, este material foi desidratado em bateria de álcool etílico e acetona, não sendo submetido à desidratação até ponto crítico em $\mathrm{CO}_{2}$, sofreu impregnação por partículas de ouro durante dois minutos (Sputter Coater), sendo examinado e fotografado em microscópio eletrônico para varredura (Stereoscam 200 - Cambridge), numa velocidade de $25 \mathrm{KV}$, para avaliação da penetração do fungo através da cutícula.

Foi observado durante o exame em microscópio eletrônico de varredura das fêmeas ingurgitadas de $\boldsymbol{B}$ microplus infectadas com o isolado 959 do fungo $\boldsymbol{M}$. anisopliae, que ocorreu: a fixação dos conídios na cutícula das fêmeas (figura 1); a germinação do conídio (figura 2); a formação do tubo germinativo a partir de conídios germinados (figura 3) e o início da dilatação da extremidade deste tubo, formando uma estrutura denominada de apressório (figura 4). Estes achados confirmam a hipótese de que este fungo entomopatogênico penetra no artrópode pela cutícula. Esta é a primeira vez que se descreve o mecanismo de penetração do M. anisopliae em carrapatos. Estes dados são similares aos resultados obtidos por ZACHARUK

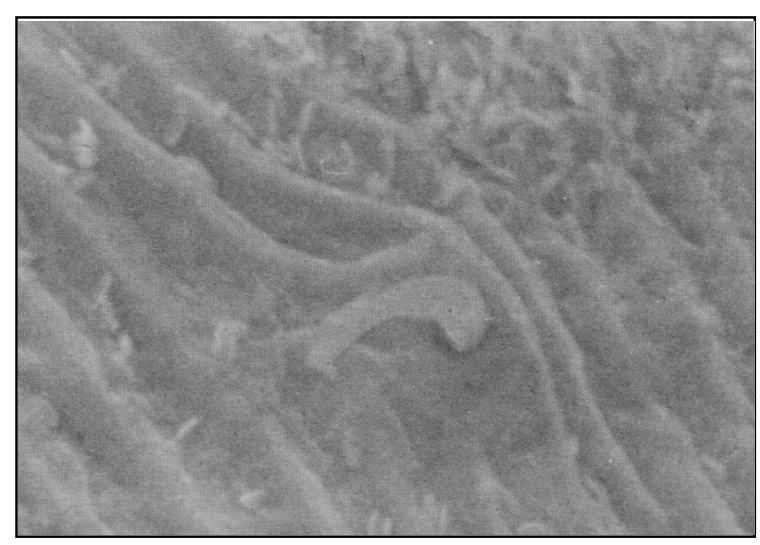

Figura 1 - Conídios de Metarhizium anisopliae aderidos à cutícula de fêmeas ingurgitadas de Boophilus microplus (802 X) 


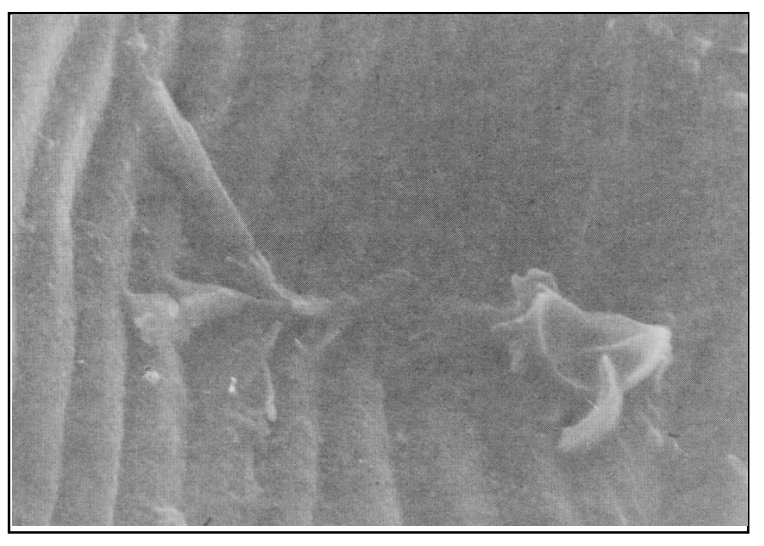

Figura 2 - Germinação de conídios de Metarhizium anisopliae aderidos à cutícula de fêmeas de Boophilus microplus $(830 \mathrm{X})$.

(1970), que observou a formação do apressório a partir da dilatação da extremidade do tubo germinativo, obtido de um conídio germinado em cutícula de uma larva de uma espécie de Coleoptera. BITTENCOURT et $\boldsymbol{a l}$. (1995a) verificaram através de três metodologias distintas que a possível forma de penetração deste fungo em carrapato é pelo tegumento, visto que no segundo dia após a infecção evidenciou hifas de $\boldsymbol{M}$. anisopliae em hemolinfa de B. microplus, a partir do quarto dia evidenciou hifas em lâminas de impressão de órgãos, enquanto o estudo histológico dos aparelhos reprodutor, digestivo e sistema respiratório não mostrou serem estas vias de penetração do fungo no carrapato, neste trabalho ficou evidenciado que as outras vias de penetração que podem ocorrer para fungos entomopatogênicos (oral e espiráculos respiratórios) não ocorre em $\boldsymbol{B}$. microplus. Paralelamente, BITTENCOURT et al.(1995b) verificaram o

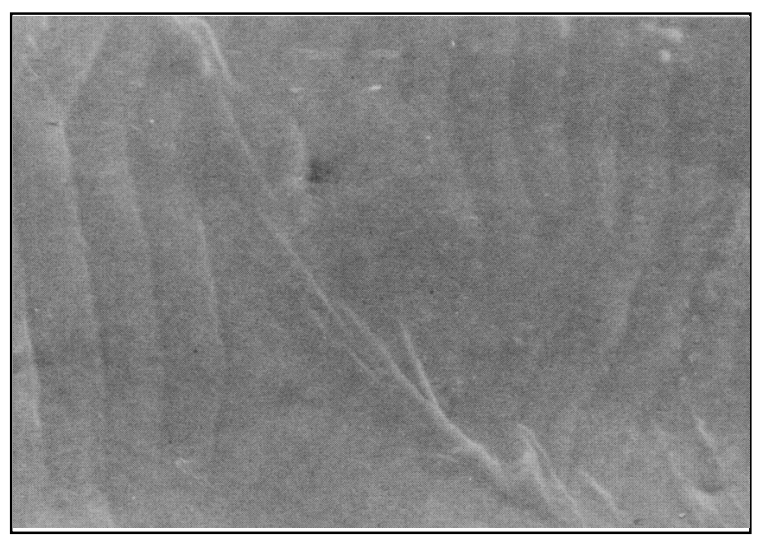

Figura 3 - Tubo germinativo de Metarhizium anisopliae aderido à cutícula de fêmeas de Boophilus microplus (645 $\mathrm{X})$.

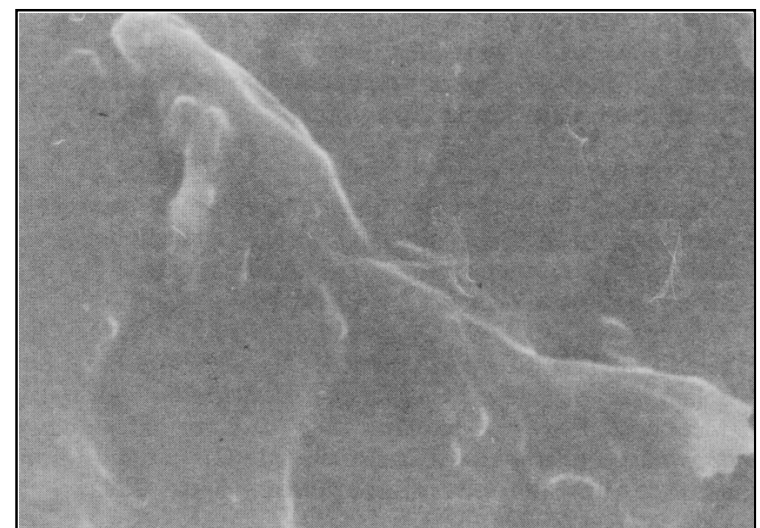

Figura 4 - Formação de apressório a partir de tubo germinativo de Metarhizium anisopliae em Boophilus microplus $(1,66 \mathrm{KX})$.

crescimento deste fungo (isolado de hemolinfa) em meio de cultura, a partir do segundo dia após a infecção. Os resultados do presente trabalho corrobora com os resultados obtidos por BITTENCOURT et al. (1995 a; b), demonstrando que a forma de infecção é através da cutícula. ALVES (1986) também afirma que a penetração normal dos fungos é pelo tegumento através de atividade enzimática ou pressão mecânica exercida pelo tubo germinativo e apressório. MADELIN $\boldsymbol{e t}$ al. (1967) também descreveram a penetração de fungos deuteromicetos através do tegumento do hospedeiro pela epicutícula e procutícula, e afirmaram que durante a penetração está envolvido o processo físico por pressão mecânica. Os resultados obtidos demonstram a capacidade do fungo $\boldsymbol{M}$. anisopliae para invasão e colonização de $\boldsymbol{B}$. microplus. A confirmação da infecção do carrapato pelo entomopatógeno, através da cutícula, indica que a forma de utilização indicada para produtos formulados a partir deste fungo é por pulverização dos ínstares susceptíveis de $\boldsymbol{B}$. microplus com as suspensões contendo conídios viáveis de $\boldsymbol{M}$. anisopliae.

\section{AGRADECIMENTOS}

A EMBRAPA - Agrobiologia pela utilização do material para microscopia eletrônica de varredura e a seu assistente de pesquisa, Geraldo Baeta da Cruz, pelo auxílio durante toda a fase experimental.

\section{REFERÊNCIAS BIBLIOGRÁFICAS}

ALVES, S. B. Controle Microbiano de Insetos. São Paulo: Manole, 1986, 407p.

BITTENCOURT, V.R.E.P., MASSARD, C.L., LIMA, A.F. Ação do fungo Metarhizium anisopliae (Metschnikoff, 1879) Sorokin, 1883, em ovos e larvas do carrapato Boophilus microplus (Canestrini, 1887). Revista Universidade Rural - Série Ciências da Vida, v. 16, p. 41-47, 1994a. 
BITTENCOURT, V.R.E.P., C.L. MASSARD, A.F. LIMA. Ação do fungo Metarhizium anisopliae sobre a fase não parasitária do ciclo biológico de Boophilus microplus. Revista Universidade Rural - Série Ciências da Vida, v. 16, p. 49-55, 1994 b.

BITTENCOURT, V.R.E.P., MASSARD, C.L., LIMA, A.F. Dinâmica da infecção do fungo Metarhizium anisopliae (Metschnikoff, 1879) Sorokin, 1883, sobre o carrapato Boophilus microplus (Canestrini, 1887). Revista Universidade Rural Série Ciências da Vida, v. 17, p. 83-88, 1995a.

BITTENCOURT, V.R.E.P., MASSARD, C.L., VIEGAS, E.C., $\boldsymbol{e}$ t al. Isolamento e cultivo do fungo Metarhizium anisopliae (Metschnikoff, 1879) Sorokin, 1883, a partir do carrapato Boophilus microplus (Canestrini, 1887) artificialmente infectado. Revista Universidade Rural - Série Ciências da Vida, v. 17, p. 55-60, 1995b.

BRUM, J.G.W. Infecção em teleógina de Boophilus microplus (Acari: Ixodidae) por Cedecea lapagei (Gresccont,1981) etiopatologia e sazonalidade. Tese de Doutorado, Universidade Federal Rural do Rio de Janeiro, Rio de Janeiro, 44 p, 1989.
DRUMMOND, R.O., GLADNEY, W.J., WHETSTONE, T.M., et al. Laboratory testing of insecticides for control of the winter tick. Journal of Economical Entomology v. 64, p. 686-688, 1971.

LIPA, J.J. Microbial control of mites and ticks. In: Microbial control of insects and mites. BURGES, H. D., N.W. HUSSEY (ed.). Microbial control of insects and mites. London: Academic Press, 1971. p. 357- 374

MADELIN, M. F., ROBINSON, R. K., WILLIAMS, R.J Appressorim-like structures in insect parasiting deuteromycetes. Journal of Invertebrate Pathology., v. 9, p. 404-412, 1967.

QUATTLEBAUM, E.C., CARNER, G.R. A technique for preparing Beauveria spp. for scanning electron microscopy. Canadian Journal of Botanic, v. 58, p. 1700-1703, 1980.

ZACHARUK, R.Y. Fine structure of the fungus Metarhizium anisopliae infecting three species of larval Elateridae (Coleoptera). II. Conidial germ tubes and appressoria. Journal of Invertebrate Pathology., v. 15, p. 81-91, 1970.

Ciência Rural, v. 29, n. 2, 1999. 